Annals of Pure and Applied Mathematics

Vol. 15, No. 2, 2017, 201-208

ISSN: 2279-087X (P), 2279-0888(online)

Published on 11 December 2017

www.researchmathsci.org

DOI: http://dx.doi.org/10.22457/apam.v15n2a6

Annals of

Pure and Applied

Mathematics

\title{
g* s- Homeomorphism and Contra g* s- Continuous Functions in Topological Space
}

N.Gomathi

Department of Mathematics, Srimad Andavan Arts \& Science College (Autonomous)

Trichy-620005, Tamilnadu, India. E-mail:gomathi198907@ gmail.com

Received 1 November 2017; accepted 9 December 2017

Abstract. In this paper, we introduced a new class of homeomorphism called gs homeomorphism and $\mathrm{g}$ *s homeomorphism. Also we investigate a new generalization of contra continuity called contra-g*s-continuous functions

Keywords: gs-homeomorphism, g*s-homeomorphism, Contra-g*s-continuous functions

AMS Mathematics Subject Classification (2010): 54C08, 54C10

\section{Introduction}

Levine [7] introduction and investigated the concept of generalized closed sets in topological space .Arya and Nour[1] defined generalized semi open [briefly gs- open] sets using semi open sets. In 1987 Bhattacharya and Lahiri [3] introduced the class of semi - generalized closed sets (sg- closed sets) Balachandran [2] introduced generalized continuous maps in topological spaces. Homomorphism plays a very important role in topology.

In 1995, Maki et al. [4] introduced the concepts of semi - generalized homeomorphisms and generalized semi homeomorphisms and studied some semi topological properties. The notion of contra continuity was introduced and investigated by Dontchev [6] Dontchev and Nohiri [8] Jafari and Noiri [5] have introduced and investigated contra. Semi continuous, functions, contra - pre- continuous functions and contra $-\alpha$-continuous functions between topological spaces.

Throughout this paper $(\mathrm{X}, \tau)$ and $(\mathrm{Y}, \sigma)$ represents the non- empty topological spaces on which no reperation axiom are assumed unless otherwise mentioned. For a subset $\mathrm{A}$ of $\mathrm{X}, \mathrm{cl}(\mathrm{A})$ and int( $\mathrm{A})$ represents the closure of $\mathrm{A}$ and interior of $\mathrm{A}$ respectively.

\section{Preliminaries}

Recall the following definitions.

Definition 2.1. A subset $(X, \tau)$ is said to be

(1) Semi-pre closed $(\beta$-closed)[6] set if int $(\operatorname{cl}(\operatorname{int}(\mathrm{A}))) \subseteq \mathrm{A}$

(2) g-closed[6] set if $\operatorname{cl}(A) \subseteq U$, whenever $A \subseteq U$ and $U$ is open in $X$

(3) w-closed[5] set if $\operatorname{cl}(\mathrm{A}) \subseteq \mathrm{U}$, whenever $\mathrm{A} \subseteq \mathrm{U}$ and $\mathrm{U}$ is semi-open in $\mathrm{X}$

(4) $\alpha$-closed[4] set if $\operatorname{cl}(\operatorname{int}(\operatorname{cl}(\mathrm{A}))) \subseteq \mathrm{A}$

(5) wg-closed[5] set if $\operatorname{cl}(\operatorname{int}(\mathrm{A}) \subseteq \mathrm{U}$, whenever $\mathrm{A} \subseteq \mathrm{U}$ and $\mathrm{U}$ is open in $\mathrm{X}$ 


\section{N.Gomathi}

(6) $\mathrm{g}^{*}$-closed[6] set if if $\operatorname{cl}(\mathrm{A}) \subseteq \mathrm{U}$, whenever $\mathrm{A} \subseteq \mathrm{U}$ and $\mathrm{U}$ is g-open in $\mathrm{X}$

(7) $\mathrm{g}^{*} \mathrm{~s}-\mathrm{closed}[6]$ set if if $\operatorname{scl}(\mathrm{A}) \subseteq \mathrm{U}$, whenever $\mathrm{A} \subseteq \mathrm{U}$ and $\mathrm{U}$ is gs-open in $\mathrm{X}$

The complements of the above mentioned closed sets are their respective open sets.

Definition 2.2. A map $\mathrm{f}: \mathrm{X} \rightarrow \mathrm{Y}$ is said to be

(1) Continuous function if $\mathrm{f}^{-1}(\mathrm{~V})$ is closed in $\mathrm{X}$ for every closed set $\mathrm{V}$ in $\mathrm{Y}$

(2) g-continuous function if $\mathrm{f}^{-1}(\mathrm{~V})$ is g-closed in $\mathrm{X}$ for every closed set $\mathrm{V}$ in $\mathrm{Y}$

(3) $\alpha$-continuous function if $\mathrm{f}^{-1}(\mathrm{~V})$ is $\alpha$-closed in $\mathrm{X}$ for every closed set $\mathrm{V}$ in $\mathrm{Y}$

(4) w-continuous function if $\mathrm{f}^{-1}(\mathrm{~V})$ is $\mathrm{w}$-closed in $\mathrm{X}$ for every closed set $\mathrm{V}$ in $\mathrm{Y}$

(5) $\mathrm{g}^{*}$ - continuous function if $\mathrm{f}^{-1}(\mathrm{~V})$ is $\mathrm{g}^{*}$-closed in $\mathrm{X}$ for every closed set $\mathrm{V}$ in $\mathrm{Y}$

(6) $\mathrm{g}^{*} \mathrm{~s}$ - continuous function if $\mathrm{f}^{-1}(\mathrm{~V})$ is $\mathrm{g}^{*} \mathrm{~s}$-closed in $\mathrm{X}$ for every closed set $\mathrm{V}$ in $\mathrm{Y}$

Definition 2.3. A bijective function $\mathrm{f}:(\mathrm{X}, \tau) \rightarrow(\mathrm{Y}, \sigma)$ is called

(1) homeomorphism if both $\mathrm{f}_{\text {and }} \mathrm{f}^{-1}$ are continuous

(2) w-homeomorphism if both $\mathrm{f}_{\text {and }} \mathrm{f}^{-1}$ are w-continuous

(3) g-homeomorphism if both $\mathrm{f}_{\text {and }} \mathrm{f}^{-1}$ are g-continuous

(4) $\alpha$-homeomorphism if both $\mathrm{f}_{\text {and }} \mathrm{f}^{-1}$ are $\alpha$-continuous

(5) $\mathrm{g}^{*}$ - homeomorphism if both $\mathrm{f}_{\text {and }} \mathrm{f}^{-1}$ are $\mathrm{g} *$-continuous

(6) $\mathrm{g}^{*} \mathrm{~s}$ - homeomorphism if both $\mathrm{f}_{\text {and }} \mathrm{f}^{-1}$ are $\mathrm{g}^{*} \mathrm{~s}$-continuous

Definition 2.4. A map $f: X \rightarrow Y$ is said to be

(1) Contra-continuous function if $\mathrm{f}^{-1}(\mathrm{~V})$ is closed in $\mathrm{X}$ for every open set $\mathrm{V}$ in $\mathrm{Y}$

(2) Contra-g-continuous function if $f^{-1}(V)$ is g-closed in $X$ for every open set $V$ in $Y$

(3) Contra- $\alpha$-continuous function if $\mathrm{f}^{-1}(\mathrm{~V})$ is $\alpha$-closed in $\mathrm{X}$ for every open set $\mathrm{V}$ in $\mathrm{Y}$

(4) Contra-W-continuous function if $\mathrm{f}^{-1}(\mathrm{~V})$ is $\mathrm{w}$-closed in $\mathrm{X}$ for every open set $\mathrm{V}$ in $\mathrm{Y}$

(5) Contra-g*- continuous function if $\mathrm{f}^{-1}(\mathrm{~V})$ is $\mathrm{g}^{*}$-closed in $\mathrm{X}$ for every open set $\mathrm{V}$ in $\mathrm{Y}$

(6) Contra-g*s- continuous function if $f^{-1}(V)$ is $g^{*} s$-closed in $X$ for every open set $V$ in $\mathrm{Y}$

\section{3. g*s-Homeomorphism}

Definition 3.1. A bijection $\mathrm{f}:(\mathrm{X}, \tau) \rightarrow(\mathrm{Y}, \sigma)$ is called $\mathrm{g}^{*} \mathrm{~s}$ - homeomorphism if $\mathrm{f}$ and $\mathrm{f}^{-1}$ are both $\mathrm{g}^{*} \mathrm{~s}$-continuous.

Example 3.2. Consider $X=Y=\{$ a.b.c $\}, \tau=\{X, \phi,\{a\},\{a, c\}\}, \sigma=\{Y, \phi,\{a\},\{b\}\}$. Let the function $\mathrm{f}: \mathrm{X} \rightarrow \mathrm{Y}$ be an identity map. Then $\mathrm{f}$ is bijective $\mathrm{Sb}^{*}$-continuous and $\mathrm{f}^{-1}$ is $\mathrm{Sb}^{*}$ continuous. Hence $\mathrm{f}$ is $\mathrm{Sb}^{*}$-homeomorphism.

Theorem 3.3. Every homeomorphism is $\mathrm{g}^{*} \mathrm{~s}$-homeomorphism but not conversely.

Proof: Let $f:(X, \tau) \rightarrow(Y, \sigma)$ be a homeomorphism. Since by the definition $\mathrm{f}_{\text {and }} \mathrm{f}^{-1}$ is $\mathrm{g}^{*} \mathrm{~s}$-continuous. Then $\mathrm{f}$ is bijection. We know that every closed set is $\mathrm{g}^{*} \mathrm{~s}$-closed. Then

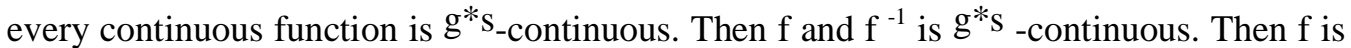
$\mathrm{g} * \mathrm{~s}$-homeomorphism.

The converse of the above theorem need not be true as seen from the following example. 
g ${ }^{*}$ s- Homeomorphism and Contra g ${ }^{*}$ s- Continuous Functions in Topological Space

Example 3.4. Consider $\mathrm{X}=\mathrm{Y}=\{\mathrm{a}, \mathrm{b}, \mathrm{c}\} \quad \tau=\{\mathrm{X}, \phi,\{\mathrm{a}\}\}, \sigma=\{\mathrm{Y}, \phi,\{\mathrm{a}\},\{\mathrm{b}\},\{\mathrm{a}, \mathrm{b}\}\}$. Let $\mathrm{f}:(\mathrm{X}, \tau) \rightarrow(\mathrm{Y}, \sigma)$ be an identity map. Let $\mathrm{A}=\{\mathrm{a}, \mathrm{c}\}$ is closed in $\mathrm{Y}$ and also it is $\mathrm{g}^{*} \mathrm{~s}-$ closed in $\mathrm{X}$. Then $\mathrm{f}$ is $\mathrm{g}^{*}{ }^{*}$-homeomorphism. But it is not a homeomorphism. Since $\{\mathrm{a}, \mathrm{c}\}$ is not closed in $\mathrm{X}$. $\mathrm{f}$ is not a homeomorphism.

Theorem 3.5. Every g*s -homeomorphism is sg -homeomorphism but not conversely Proof: Let $\mathrm{f}:\left(\mathrm{X},{ }^{\tau}\right) \rightarrow(\mathrm{Y}, \sigma)$ be a $\mathrm{g}^{*} \mathrm{~s}$ - homeomorphism. Since by the definition $\mathrm{f}$ anf $\mathrm{f}-1$ is sg-continuous. Then $\mathrm{f}$ is bijection. We know that every $\mathrm{g}^{*} \mathrm{~s}$-closed set is sg-closed . Then every $g^{*} s$-continuous function is sg-continuous. Then $f$ and $f-$ 1 is sg-continuous. Then $\mathrm{f}$ is sg-homeomorphism.

The converse of the above theorem need not be true as seen from the following example.

Example 3.6. Consider $\mathrm{X}=\mathrm{Y}=\{\mathrm{a}, \mathrm{b}, \mathrm{c},\} \quad \tau=\{\mathrm{X}, \phi,\{\mathrm{b}\},\{\mathrm{a}, \mathrm{c}\}\}, \sigma=\{\mathrm{Y}, \phi,\{\mathrm{a}, \mathrm{b}\}\}$. Let f:X $\rightarrow \mathrm{Y}$ be an identity map . Let $\mathrm{A}=\{\mathrm{a}, \mathrm{c}\}$ is closed in $\mathrm{Y}$ and also it is sg-closed in $\mathrm{X}$ Then $\mathrm{f}$ is sg-homeomorphism. But it is not a $\mathrm{g} * \mathrm{~s}$-homeomorphism. Since the inverse image $\{\mathrm{a}, \mathrm{c}\}$ is not $\mathrm{g}^{*} \mathrm{~s}$-closed in $\mathrm{X}$.

Theorem 3.7. Every $\mathrm{g}$ *s -homeomorphism is gs -homeomorphism but not conversely Proof: Let $\mathrm{f}:(\mathrm{X}, \tau) \rightarrow(\mathrm{Y}, \sigma)$ be a $\mathrm{g}^{*} \mathrm{~s}$ - homeomorphism. Since by the definition $\mathrm{f}$ anf $\mathrm{f}^{-1}$ is gs-continuous. Then $\mathrm{f}$ is bijection. We know that every $\mathrm{g}^{*} \mathrm{~s}$-closed set is

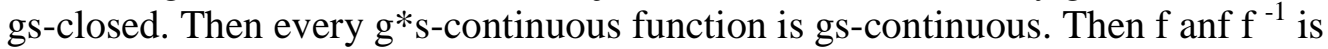
gs-continuous. Then $\mathrm{f}$ is gs-homeomorphism.

The converse of the above theorem need not be true as seen from the following example.

Example 3.8. Consider $\mathrm{X}=\mathrm{Y}=\{\mathrm{a}, \mathrm{b}, \mathrm{c}, \mathrm{d}\} \quad \tau=\{\mathrm{X}, \phi,\{\mathrm{a}\},\{\mathrm{b}\},\{\mathrm{a}, \mathrm{b}\}\{\mathrm{a}, \mathrm{b}, \mathrm{c}\}\}, \quad \sigma=\{\mathrm{Y}, \phi$ $,\{a\},\{d\},\{c, d\},\{a, c, d\}\}$. Let $f: X \rightarrow Y$ be an identity map .Let $A=\{a, b\}$ is closed in $X$ and also it is gs-closed in $\mathrm{Y}$. Then $\mathrm{f}$ is gs-homeomorphism. But it is not a $\mathrm{g}^{*} \mathrm{~s}-$ homeomorphism. Since the inverse image $\{\mathrm{a}, \mathrm{b}\}$ is not $\mathrm{g} * \mathrm{~s}$-closed in $\mathrm{X}$.

Theorem 3.9. Let $\mathrm{f}:(\mathrm{X}, \tau) \rightarrow(\mathrm{Y}, \sigma)$ be a bijective $\mathrm{g}^{*}$ s-continuous map,then the following statements are equivalent (i) $\mathrm{f}$ is an $\mathrm{g}^{*} \mathrm{~s}$-open map. (ii) $\mathrm{f}$ is an $\mathrm{g}^{*} \mathrm{~s}$ homeomorphism . (iii) $\mathrm{f}$ is an $\mathrm{g}^{*} \mathrm{~s}$-closed map.

Proof: (i) implies (ii) Let $\mathrm{f}^{-1}:(\mathrm{X}, \tau) \rightarrow(\mathrm{Y}, \sigma)$ be a bijective $\mathrm{g}$ *s -continuous map .Let $\mathrm{F}$ be an closed map in $(X, \tau)$. Then $X-F$ is open in $(X, \tau)$. Since $f$ is $g^{*} s$-open.$f(X-F)$ is $\mathrm{g}^{*} \mathrm{~s}$-open in $(\mathrm{Y}, \sigma) . \mathrm{f}(\mathrm{F})$ is $\mathrm{g}^{*} \mathrm{~s}$-closed in $(\mathrm{Y}, \sigma) \mathrm{f}$ is $\mathrm{g}^{*} \mathrm{~s}$-continuous. Now $\left(\left(\mathrm{f}^{-1}\right)^{-1}(\mathrm{~F})\right)$ is $\mathrm{g}^{*} \mathrm{~s}$-closed in $(\mathrm{Y}, \sigma) . \mathrm{f}^{-1}$ is $\mathrm{g}^{*} \mathrm{~s}$-continuous. Then $\mathrm{f}$ and $\mathrm{f}^{-1}$ is $\mathrm{g}^{*} \mathrm{~s}$-continuous. $\mathrm{f}$ is an $\mathrm{g}$ * $\mathrm{s}$-homeomorphism (ii) implies (iii) Suppose $\mathrm{f}$ is an $\mathrm{g} * \mathrm{~s}$-homeomorphism. By the definition $\mathrm{f}$ is bijective, $\mathrm{f}_{\text {and }} \mathrm{f}^{-1}$ are $\mathrm{g}^{*} \mathrm{~s}$-continuous .Let $\mathrm{f}$ be an $\mathrm{g}^{*} \mathrm{~s}$ - closed set in (X, $\tau)$. Since $\mathrm{f}_{\text {and }} \mathrm{f}^{-1}$ are $\mathrm{g}^{*} \mathrm{~s}$-continuous. Then $\left(\mathrm{f}^{-1}\right)^{-1}(\mathrm{~F})=\mathrm{f}(\mathrm{F})$ is $\mathrm{g}^{*} \mathrm{~s}$-closed in $(\mathrm{Y}, \sigma)$. Then $\mathrm{f}$ is $\mathrm{g}^{*} \mathrm{~s}$-closed map . (iiii) implies (i) Let $\mathrm{f}$ is an $\mathrm{g}^{*} \mathrm{~s}$-closed map. Let $\mathrm{U}$ is an $\mathrm{g}^{*} \mathrm{~s}$ 
N.Gomathi

-open in $X$. Then $X-U$ is $g^{*} s$-closed in $Y$. Since $f$ is $g^{*} s$-closed. $f(X-U)$ is $g^{*} s$-closed in $\mathrm{Y}$. $\mathrm{Y}-\mathrm{f}(\mathrm{U})$ is $\mathrm{g}{ }^{*} \mathrm{~s}$-closed in $\mathrm{Y} . \mathrm{f}(\mathrm{U})$ is $\mathrm{g}$ *s -open in $\mathrm{Y}$. $\mathrm{f}$ is an $\mathrm{g} * \mathrm{~s}$-open map .

Definition 3.10. A bijection $\mathrm{f}:(\mathrm{X}, \tau) \rightarrow(\mathrm{Y}, \sigma)$ is called $\mathrm{g} * \mathrm{~s}$-irresolute if $\mathrm{f}^{-1}(\mathrm{~V})$ is $\mathrm{g}^{*} \mathrm{~s}$ closed in $(\mathrm{X}, \tau)$ for every $\mathrm{g}^{*} \mathrm{~s}$-closed $\mathrm{V}$ in $(\mathrm{Y}, \sigma)$.

Example 3.11. Consider $X=Y=\{$ a.b.c. $\}, \tau=\{X, \phi,\{a\},\{a, c\}\}, \sigma=\{Y, \phi,\{a\}\}$. Let f: $X$ $\rightarrow \mathrm{Y}$ be an identity map . Let $\mathrm{A}=\{\mathrm{c}\}$ is $\mathrm{g}^{*}$ s-clsoed in $\mathrm{Y}$. Then $\mathrm{f}^{-1}(\{\mathrm{c}\})=\{\mathrm{c}\}$ is also $\mathrm{g}^{*} \mathrm{~s}-$ closed in $\mathrm{X}$. $\mathrm{f}$ is $\mathrm{g} *$ s-Irresolute.

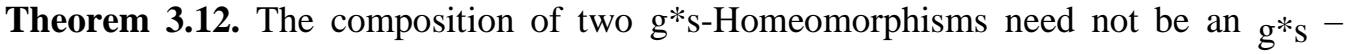
Homeomorphism.

Proof: Let $\mathrm{f}:(\mathrm{X}, \tau) \rightarrow(\mathrm{Y}, \sigma)$ and $\mathrm{g}:(\mathrm{Y}, \sigma) \rightarrow(\mathrm{Z}, \zeta)$ be an $\mathrm{g}$ *s-Homeomorphism. By $\mathrm{g}^{*} \mathrm{~s}$-Homeomorphism, $\mathrm{f}$ and $\mathrm{f}^{-1}$ are both $\mathrm{g}^{*} \mathrm{~s}$-continuous . We know that ,The composition of two continuous functions need not be a continuous function. Since the composition of two $g^{*} s$-continuous functions need not be a $g^{*} s$-continuous function. Therefore $g^{\circ} f$ is need not be an $\mathrm{g}^{*} \mathrm{~s}-\mathrm{homeomorphism}$.

Example 3.13. Let $\mathrm{X}=\mathrm{Y}=\mathrm{Z}=\{\mathrm{a}, \mathrm{b}, \mathrm{c},\} \quad \tau=\{\mathrm{X}, \phi,\{\mathrm{a}\},\{\mathrm{a}, \mathrm{c}\}\}, \sigma=\{\mathrm{Y}, \phi,\{\mathrm{a}\},\{\mathrm{b}\},\{\mathrm{a}, \mathrm{b}\}\}, \xi$ $=\{\mathrm{Z}, \phi,\{\mathrm{a}\}\}$.Let $\mathrm{f}$ and $\mathrm{g}$ be an identity map. Here $\mathrm{f}$ and $\mathrm{g}$ are $\mathrm{g}{ }^{*} \mathrm{~s}$-Homeomorphism. But $\mathrm{g}^{\circ} \mathrm{f}$ is not an $\mathrm{g}^{*} \mathrm{~s}$-homeomorphism, Since the inverse image of $\mathrm{X}$ in $\{\mathrm{b}, \mathrm{c}\}$ is not $\mathrm{g}{ }^{*} \mathrm{~s}$ closed in X.

Definition 3.14. A Space $X$ is said to be $g^{*} s$-compact if every cover of $X$ by $g^{*}$ s-open sets has a finite sub cover.

Definition 3.15. Let $x$ be a point of $(X, \tau)$ and $V$ be a subset of $X$. Then $V$ is called a $\mathrm{g}^{*}$ s-neighborhood of $\mathrm{x}$ in $(\mathrm{X}, \tau)$ if there exist a $\mathrm{g}^{*} \mathrm{~s}$-open set $\mathrm{U}$ of $(\mathrm{X}, \tau)$ such that $\mathrm{x} \in \mathrm{U}$ $\subset \mathrm{V}$.

Definition 3.16. A topological space $(X, \tau)$ is called $g * s-H a u s d o r f f$ if for each pair $x, y$ of distinct points of $\mathrm{X}$, there exists $\mathrm{g}^{*}$ s-neighborhoods $\mathrm{U}_{1}$ and $\mathrm{U}_{2}$ of $\mathrm{x}$ and $\mathrm{Y}$ respectively, that are disjoint.

Theorem 3.17. Let $\mathrm{X}$ be $\mathrm{g}$ *s-compact and set $\mathrm{Y}$ be a Hausdorff space. If $\mathrm{f}:(\mathrm{X}, \tau) \rightarrow(\mathrm{Y}$, $\sigma$ ) is $\mathrm{g}^{*}$ s-continuous, $\mathrm{g} * \mathrm{~s}$-irresolute and bijective then $\mathrm{f}$ is $\mathrm{g} * \mathrm{~s}$-homeomorphism.

Proof: Let A be a $g * s$-closed subset of the $g *$ s-compact space $X$. Then A is $g * s-$ compact. But $f$ is $g^{*} s$-irresolute . Hence $f(A)$ is $g^{*} s$-compact . Take $g=f^{-1}$. Then $g^{-1}(A)$ is $\mathrm{g}^{*}$ s-closed .We know that ,consequently $\mathrm{g}$ is an $\mathrm{g}{ }^{*} \mathrm{~s}$-irresolute map. Then $\mathrm{f}^{-1}$ is $\mathrm{g}^{*} \mathrm{~s}$ irresolute. $\mathrm{f}$ is $\mathrm{g} * \mathrm{~s}$-homeomorphism.

Thoerem 3.18. If $\mathrm{f}:(\mathrm{X}, \tau) \rightarrow(\mathrm{Y}, \sigma)$ is a $\mathrm{g}^{*} \mathrm{~s}-\mathrm{Homeomorphism}$ then $\mathrm{g}^{*} \mathrm{~s}-\mathrm{cl}\left(\mathrm{f}^{-1}(\mathrm{~B})\right)=\mathrm{f}^{-}$ ${ }^{1}\left(\mathrm{~g}^{*} \mathrm{~s}-\mathrm{cl}(\mathrm{B})\right)$ for all $\mathrm{B} \subseteq \mathrm{Y}$ is $\mathrm{g}^{*} \mathrm{~s}$-closed. 
$\mathrm{g}^{*} \mathrm{~s}-$ Homeomorphism and Contra $\mathrm{g}$ " s- Continuous Functions in Topological Space

Proof: If $\mathrm{f}:(\mathrm{X}, \tau) \rightarrow(\mathrm{Y}, \sigma)$ is a $\mathrm{g}{ }^{*} \mathrm{~s}$-Homeomorphism. Since $\mathrm{f}$ is $\mathrm{g}{ }^{*} \mathrm{~s}$-Homeomorphism. $\mathrm{f}$ and $\mathrm{f}^{-1}$ is both are $\mathrm{g}^{*} \mathrm{~s}$-irresolute. $\mathrm{g}^{*} \mathrm{~s}-\mathrm{cl}(\mathrm{f}(\mathrm{B}))$ is closed in $(\mathrm{Y}, \sigma) \cdot \mathrm{f}^{-1}\left(\mathrm{~g}^{*} \mathrm{~s}-\mathrm{cl}(\mathrm{f}(\mathrm{B}))\right)$ is $\mathrm{g}^{*} \mathrm{~s}$-closed in $(\mathrm{X}, \tau)$. Thus $\mathrm{g}^{*} \mathrm{~s}-\mathrm{cl}\left(\mathrm{f}^{-1}(\mathrm{~B})\right) \subseteq \mathrm{f}^{-1}\left(\mathrm{~g}^{*} \mathrm{~s}\right.$-cl(B)$)$. Again $\mathrm{f}^{-1}$ is irresolute $\cdot \mathrm{g}^{*} \mathrm{~s}-$ $\mathrm{cl}\left(\mathrm{f}^{-1}(\mathrm{~B})\right)$ is $\mathrm{g}^{*} \mathrm{~s}-\mathrm{closed}$ in $(\mathrm{X}, \tau) .\left(\left(\mathrm{f}^{-1}\right)^{-1}\right) \mathrm{g}^{*} \mathrm{~s}-\mathrm{cl}\left(\mathrm{f}^{-1}(\mathrm{~B})\right)=\mathrm{f}\left(\mathrm{g} * \mathrm{~s}-\mathrm{cl}\left(\mathrm{f}^{-1}(\mathrm{~B})\right)\right)$ is $\mathrm{g} * \mathrm{~s}$-closed in $(\mathrm{X}, \tau) . \mathrm{B}=\mathrm{f}\left(\mathrm{g}^{*} \mathrm{~s}-\mathrm{cl}\left(\mathrm{f}^{-1}(\mathrm{~B})\right)\right)$. Hence $\mathrm{g}^{*} \mathrm{~s}-\mathrm{cl}\left(\mathrm{f}^{-1}(\mathrm{~B})\right)=\mathrm{f}^{-1}\left(\mathrm{~g}^{*} \mathrm{~s}-\mathrm{cl}(\mathrm{B})\right)$.

Theorem 3.19. If $\mathrm{f}:(\mathrm{X}, \tau) \rightarrow(\mathrm{Y}, \sigma)$ is an $\mathrm{g}^{*} \mathrm{~s}-$ Homeomorphism then $\mathrm{g}^{*} \mathrm{~s}-\mathrm{cl}(\mathrm{f}(\mathrm{B}))=\mathrm{f}\left(\mathrm{g}^{*} \mathrm{~s}-\right.$ $\mathrm{cl}(\mathrm{B}))$ for all $\mathrm{B} \subseteq \mathrm{X}$.

Proof: If $\mathrm{f:}(\mathrm{X}, \tau) \rightarrow(\mathrm{Y}, \sigma)$ is an $\mathrm{g}^{*} \mathrm{~s}$-Homeomorphism. Since $\mathrm{f:}(\mathrm{X}, \tau) \rightarrow(\mathrm{Y}, \sigma)$ is an $\mathrm{g}^{*} \mathrm{~s}$-Homeomorphism. Then $\mathrm{f}^{-1}:(\mathrm{Y}, \sigma) \rightarrow(\mathrm{X}, \tau)$ is also an $\mathrm{g}^{*} \mathrm{~s}$-Homeomorphism. Since $\mathrm{f}$ is an $\mathrm{g}$ *s-Homeomorphism then $\mathrm{f}$ and $\mathrm{f}^{-1}$ is both are $\mathrm{g} * \mathrm{~s}$-Irresolute. ( $\mathrm{g} * \mathrm{~s}-\mathrm{cl}(\mathrm{f}(\mathrm{B}))$ is $\mathrm{g}^{*} \mathrm{~s}-$ closed in $(\mathrm{Y}, \sigma) \cdot \mathrm{f}^{-1} \mathrm{~g}^{*} \mathrm{~s}-\mathrm{cl}(\mathrm{f}(\mathrm{B}))$ is $\mathrm{g}^{*} \mathrm{~s}-\mathrm{closed}$ in $(\mathrm{X}, \tau)$. $\left(\mathrm{g}^{*} \mathrm{~s}-\mathrm{int}(\mathrm{A})\right)^{\mathrm{c}}=\mathrm{g}^{*} \mathrm{~s}-\mathrm{cl}\left(\mathrm{A}^{\mathrm{c}}\right)$. $\left(\mathrm{g}^{*} \mathrm{~s}-\right.$ $\operatorname{int}(B))^{c}=\left(g^{*} s-c l\left(B^{c}\right)\right)^{c}$. Then $f\left(g^{*} s-i n t(B)=f\left(\left(g^{*} s-c l\left(B^{c}\right)\right)^{c}\right)=\left(\left(g^{*} s-c l\left(B^{c}\right)\right)\right)^{c}=g^{*} s-\right.$ $\left.\operatorname{cl}\left(f\left(B^{c}\right)\right)\right)^{c}=g^{*} s-i n t(f(B))$. Therefore, $g^{*} s-c l(f(B))=f(g * s-c l(B))$.

Theorem 3.20. The set $\mathrm{g}^{*} \mathrm{~s}-\mathrm{h}(\mathrm{X}, \tau)$ is a group under the composition of maps.

Proof: Define a binary operation * as follows . ${ }^{*}: \mathrm{g}^{*} \mathrm{~s}-\mathrm{h}(\mathrm{X}, \tau) \times \mathrm{g} * \mathrm{~s}-\mathrm{h}(\mathrm{X}, \tau) \rightarrow \mathrm{g}{ }^{*} \mathrm{~s}-$ $\mathrm{h}(\mathrm{X}, \tau) \mathrm{f}^{*} \mathrm{~g}=\mathrm{g} \circ \mathrm{f}$ for all $\mathrm{f}, \mathrm{g} \in \mathrm{g} \mathrm{g}^{*} \mathrm{~s}-\mathrm{h}(\mathrm{X}, \tau)$. ' $\circ$ ' is the usual operation of composition of maps $\mathrm{g} \circ \mathrm{f} \in \mathrm{g} * \mathrm{~s}-\mathrm{h}(\mathrm{X}, \tau)$. We Know That, the composition of maps is associative and the identity map.

$\mathrm{I}:(\mathrm{X}, \tau) \times(\mathrm{X}, \tau) \in \mathrm{g} * \mathrm{~s}-\mathrm{h}(\mathrm{X}, \tau)$ serves as the identity element. If $\mathrm{f} \in \mathrm{g} * \mathrm{~s}-\mathrm{h}(\mathrm{X}, \tau)$ then $\mathrm{f}^{-1} \in \mathrm{g}^{*} \mathrm{~s}-\mathrm{h}(\mathrm{X}, \tau)$ such that $\mathrm{f} \circ \mathrm{f}^{-1}=\mathrm{f}^{-1} \circ \mathrm{f}=\mathrm{I}$, and so inverse exists for each element of $\mathrm{g}^{*} \mathrm{~s}-\mathrm{h}(\mathrm{X}, \tau)$ is a group under composition of maps. $\mathrm{g}^{*} \mathrm{~s}-\mathrm{h}(\mathrm{X}, \tau)$ is a group under the composition of maps.

Thoerem 3.21. Let $\mathrm{f}:(\mathrm{X}, \tau) \rightarrow(\mathrm{Y}, \sigma)$ be an $\mathrm{g}^{*} \mathrm{~s}$-Homeomorphism . Then $\mathrm{f}$ induces an isomorphism from the group $\mathrm{g} * \mathrm{~s}-\mathrm{h}(\mathrm{X}, \tau)$ onto the group $\mathrm{g} * \mathrm{~s}-\mathrm{h}(\mathrm{X}, \tau)$.

Proof: Let $\mathrm{f}:(\mathrm{X}, \tau) \rightarrow(\mathrm{Y}, \sigma)$ be an $\mathrm{g}^{*} \mathrm{~s}$-Homeomorphism . We define $\mathrm{I}_{\mathrm{f}}: \mathrm{g}{ }^{*} \mathrm{~s}-\mathrm{h}(\mathrm{X}, \tau) \rightarrow$ $\mathrm{g}^{*} \mathrm{~s}-\mathrm{h}(\mathrm{X}, \tau)$. Now ' $\mathrm{f}$ ' induces an isomorphism from the group $\mathrm{I}_{\mathrm{f}}(\mathrm{h})=\mathrm{f} \circ \mathrm{h} \circ \mathrm{f}^{-1}$ for every $\mathrm{h}$ $\in \mathrm{g} * \mathrm{~s}-\mathrm{h}(\mathrm{X}, \tau)$. Since $\mathrm{I}_{\mathrm{f}}$ is a bijection. Further for every $\mathrm{h}_{1}, \mathrm{~h}_{2} \in \mathrm{g} * \mathrm{~s}-\mathrm{h}(X, \tau) . \mathrm{I}_{\mathrm{f}}\left(\mathrm{h}_{1} \circ \mathrm{h}_{2}\right)=\mathrm{f}$ $\circ\left(h_{1} \circ h_{2}\right) \circ f^{-1 .} I_{f}\left(h_{1} \circ h_{2}\right)=\left(f \circ h_{1} \circ f^{-1}\right) \circ\left(f \circ h_{2} \circ f^{-1}\right) I_{f}\left(h_{1} \circ h_{2}\right)=I_{f}\left(h_{1}\right) * I_{f}\left(h_{2}\right)$ Thus $I_{f}$ is a Homeomorphism and so it is an isomorphism induced by ' $\mathrm{f}$ '. $\mathrm{f}$ induces an isomorphism from the group $\mathrm{g} * \mathrm{~s}-\mathrm{h}(\mathrm{X}, \tau)$ onto the group $\mathrm{Sb}^{*}-\mathrm{h}(\mathrm{X}, \tau)$.

\section{Contra $g^{*} \mathrm{~s}$ - continuous functions}

In this section I introduce the concept of contra $\mathrm{g}^{*} \mathrm{~s}$ - continuous function in topological spaces.

Definition 4.1. A function $\mathrm{f}:(\mathrm{X}, \tau) \rightarrow(\mathrm{Y}, \sigma)$ is called contra $\mathrm{g}^{*} \mathrm{~s}-$ continuous if the inverse image of every open set in $\mathrm{Y}$ is $\mathrm{g}^{*} \mathrm{~s}-$ closed in $\mathrm{X}$.

Theorem 4.2. Every contra-continuous function is contra $\mathrm{g}^{*} \mathrm{~s}$ continuous but not conversely. 
N.Gomathi

Proof: Let $\mathrm{f}:(\mathrm{X}, \tau) \rightarrow(\mathrm{Y}, \sigma)$ be contra continuous. Let $\mathrm{V}$ be any open set in $\mathrm{Y}$. Then the inverse image $f^{-1}(V)$ is closed in $X$. since every closed set in $g^{*} s-$ closed, $f^{-1}(V)$ is $\mathrm{g}^{*} \mathrm{~s}$-closed in $\mathrm{X}$. Therefore $\mathrm{f}$ is contra $\mathrm{g}^{*} \mathrm{~s}-$ continuous.

Example 4.3. Consider $\mathrm{X}=\mathrm{Y}=\{\mathrm{a}, \mathrm{b}, \mathrm{c}, \mathrm{d}\} \quad \tau=\{\mathrm{X}, \phi,\{\mathrm{a}\},\{\mathrm{b}\},\{\mathrm{a}, \mathrm{b}\}\{\mathrm{a}, \mathrm{b}, \mathrm{c}\}\}, \quad \sigma=\{\mathrm{Y}, \quad \phi$ $,\{a\},\{a, b\}\}$. Let $f$ be an identity map. Here $f$ is contra-g*s-continuous but not contracontinuous. Since the inverse image of $\{\mathrm{a}\}$ is not closed in X.

Theorem 4.4. Every contra ${ }^{*}$ s continuous function is contra gs continuous function but not conversely.

Proof: Let $\mathrm{f}:(\mathrm{X}, \tau) \rightarrow(\mathrm{Y}, \sigma)$ be contra ${ }^{*}{ }^{*}$ s continuous Let $\mathrm{V}$ be any open set in $\mathrm{Y}$. then the inverse image $\mathrm{f}^{-1}(\mathrm{~V})$ is $\mathrm{g}^{*}$ s closed in $\mathrm{X}$. Since every $\mathrm{g}^{*} \mathrm{~s}$-closed set is gs closed, $\mathrm{f}^{-1}(\mathrm{~V})$ is gs- closed in $\mathrm{X}$. Therefore $\mathrm{f}$ is contra-gs -continuous.

Example 4.5. Consider $\mathrm{X}=\mathrm{Y}=\{\mathrm{a}, \mathrm{b}, \mathrm{c}\} \quad \tau=\{\mathrm{X}, \phi,\{\mathrm{a}\},\{\mathrm{a}, \mathrm{c}\}\}, \sigma=\{\mathrm{Y}, \phi,\{\mathrm{a}\}\}$. Let $\mathrm{f}$ be an identity map. Here $f$ is contra-gs-continuous but not contra-g*s-continuous. Since the inverse image of $\{a, b\}$ is not $g^{*}$ s-closed in $\mathrm{X}$.

Theorem 4.6. Every contra $\mathrm{g}^{*} \mathrm{~s}-$ continuous function is contra sg-continuous function but not conversely.

Proof: Let $\mathrm{f}:(\mathrm{X}, \tau) \rightarrow(\mathrm{Y}, \sigma)$ be contra $\mathrm{g}^{*} \mathrm{~s}-$ continuous Let $\mathrm{V}$ be any open set in $\mathrm{Y}$. then the inverse image $\mathrm{f}^{-1}(\mathrm{~V})$ is $\mathrm{g}^{*} \mathrm{~s}$-closed in $\mathrm{X}$. since every $\mathrm{g}^{*}$ s-closed set is sgclosed, $\mathrm{f}^{-1}(\mathrm{~V})$ is sg -closed in $\mathrm{X}$. Therefore $\mathrm{f}$ is contra sg-continuous function.

Example 4.7. Consider $\mathrm{X}=\mathrm{Y}=\{\mathrm{a}, \mathrm{b}\} \quad \tau=\{\mathrm{X}, \phi,\{\mathrm{b}\}\}, \sigma=\{\mathrm{Y}, \phi,\{\mathrm{a}\}\}$. Let $\mathrm{f}$ be an identity map. Here $\mathrm{f}$ is contra-sg-continuous but not contra-g*s-continuous. Since the inverse image of $\{a\}$ is not $g *$ s-closed in $X$.

Remark 4.8. Independentness of contra-g*s-continuity

(i) Contra-g*s continuous function is independent to contra-g-continuous function

(ii) Contra-g*s continuous function is independent to contra-g*-continuous function

(iii) Contra-g*s continuous function is independent to contra-w-continuous function

(iv) Contra-g*s continuous function is independent to contra-pre-continuous function.

The below examples proved the independentness of contra-g*s-continuity

Example 4.9. Consider $\mathrm{X}=\mathrm{Y}=\{\mathrm{a}, \mathrm{b}, \mathrm{c}, \mathrm{d}\} \quad \tau=\{\mathrm{X}, \phi,\{\mathrm{a}\},\{\mathrm{b}\},\{\mathrm{a}, \mathrm{b}\}\{\mathrm{a}, \mathrm{b}, \mathrm{c}\}\}$,. Let $\mathrm{f}: \mathrm{X} \rightarrow \mathrm{Y}$ be an identity map .Here $\mathrm{f}$ is contra-g*s-continuous but not contra-g-continuous. Since the inverse image of $\{b, c\}$ is not g-closed in $\mathrm{x}$. In this space $\sigma=\{\mathrm{Y}, \phi,\{\mathrm{a}\},\{\mathrm{b}\},\{\mathrm{a}, \mathrm{b}\}$, \} and $\mathrm{f}$ be an identity map, $\mathrm{f}$ is contra-g-continuous but not contra-g*s-continuous . Since the inverse image of $\{\mathrm{a}, \mathrm{b}, \mathrm{d}\}$ is not $\mathrm{g}^{*} \mathrm{~s}$-closed in $\mathrm{X}$. 
$\mathrm{g}^{*}$ s- Homeomorphism and Contra $\mathrm{g}^{*} \mathrm{~s}$ - Continuous Functions in Topological Space

Example 4.10. Consider $\mathrm{X}=\mathrm{Y}=\{\mathrm{a}, \mathrm{b}, \mathrm{c}\} \quad \tau=\{\mathrm{X}, \phi,\{\mathrm{a}\},\{\mathrm{a}, \mathrm{b}\}\}$. Let $\mathrm{f}: \mathrm{X} \rightarrow \mathrm{Y}$ be an identity map .Here $\mathrm{f}$ is contra-g*s-continuous but not contra-g*-continuous -since the inverse image of $\{\mathrm{b}\}$ is not $\mathrm{g}^{*}$-closed in $\mathrm{x}$. In this space $\sigma=\{\mathrm{Y}, \phi,\{\mathrm{b}\},\{\mathrm{a}, \mathrm{c}\}\}$ and $\mathrm{f}$ be an identity map, $\mathrm{f}$ is contra-g*-continuous but not contra-g*s-continuous. Since the inverse image of $\{\mathrm{a}, \mathrm{c}\}$ is not $\mathrm{g} * \mathrm{~s}$-closed in $\mathrm{X}$.

Example 4.11. Consider $\mathrm{X}=\mathrm{Y}=\{\mathrm{a}, \mathrm{b}, \mathrm{c}, \mathrm{d}\} \quad \tau=\{\mathrm{X}, \phi,\{\mathrm{a}\},\{\mathrm{b}\},\{\mathrm{a}, \mathrm{b}\}\{\mathrm{a}, \mathrm{b}, \mathrm{c}\}\}$. Let $\mathrm{f}$ : $\rightarrow \mathrm{Y}$ be an identity map. Here $\mathrm{f}$ is contra-g*s-continuous but not contra-pre continuous. Since the inverse image of $\{a\}$ is not pre-closed in $\mathrm{x}$. In this space $\sigma$ $=\{Y, \varphi,\{a\},\{b\},\{a, b\}\}$ and we define a map $f(a)=b, f(b)=c, f(c)=a, f(d)=d$. Here $f$ is contra-pre-continuous but not contra-g*s-continuous. Since the inverse image of $\{c, d\}$ is not $g^{*} s-c l o s e d$ in $X$.

Example 4.12. Consider $\mathrm{X}=\mathrm{Y}=\{\mathrm{a}, \mathrm{b}, \mathrm{c},\} \quad \tau=\{\mathrm{X}, \phi,\{\mathrm{a}\},\{\mathrm{a}, \mathrm{c}\}\}$. Let $\mathrm{f}: \mathrm{X} \rightarrow \mathrm{Y}$ be an identity map .Here $\mathrm{f}$ is contra-g*s-continuous but not contra-w-continuous. Since the inverse image of $\{\mathrm{a}, \mathrm{c}\}$ is not $\mathrm{w}$-closed in $\mathrm{x}$. In this space $\sigma=\{\mathrm{Y}, \varphi,\{\mathrm{a}\},\{\mathrm{a}, \mathrm{b}\}\}$ and $\mathrm{f}$ be an identity map. Here $\mathrm{f}$ is contra-w-continuous but not contra-g*s-continuous. Since the inverse image of $\{a, b\}$ is not $g^{*}$ s-closed in $\mathrm{X}$.

Remark 4.13. The composition of two contra-g*s-continuous functions need not be an contra-g*s-continuous function.

Example 4.14. Let $\mathrm{X}=\mathrm{Y}=\mathrm{Z}=\{\mathrm{a}, \mathrm{b}, \mathrm{c}, \mathrm{d}\} \quad \tau=\{\mathrm{X}, \varphi,\{\mathrm{a}\},\{\mathrm{b}\},\{\mathrm{a}, \mathrm{b}\},\{\mathrm{a}, \mathrm{b}, \mathrm{c}\}\}, \sigma=\{\mathrm{Y}$, $\varphi,\{a\},\{b\},\{a, b\}\}, \xi=\{Z, \varphi,\{a\}\}$.Let $f$ and $g$ be an identity map. Here $f$ and $g$ are $g * s-$ Homeomorphism. But $\mathrm{g} \circ \mathrm{f}$ is not an $\mathrm{g}^{*} \mathrm{~s}$-homeomorphism. Since the inverse image of $\mathrm{X}$ in $\{$ a.c $\}$ is not $\mathrm{g}^{*} \mathrm{~s}$-closed in $\mathrm{X}$.

Theorem 4.15. If a map $\mathrm{f}:\left(\mathrm{X},{ }^{\tau}\right) \rightarrow(\mathrm{Y}, \sigma)$ is $\mathrm{g} * \mathrm{~s}$-irresolute map the $\mathrm{g}:(\mathrm{Y}, \sigma) \rightarrow(\mathrm{Z}$, $\zeta$ ) is $\mathrm{g}^{*}$ s-continuous map then $\mathrm{g}{ }^{\circ} \mathrm{f}:(\mathrm{X}, \tau) \rightarrow(\mathrm{Z}, \zeta)$ is contra-g*s-continuous function

Proof: Let $\mathrm{F}$ be an open set in $(\mathrm{Z}, \zeta)$. Then $\mathrm{g}^{-1}(\mathrm{~F})$ in $\mathrm{g}^{*}$ s-closed in $(\mathrm{Y}, \sigma)$, because $\mathrm{g}$ is contra-g*s-continuous. Since $f$ is $g^{*} s$-irresolute, $f^{-1}\left(g^{-1}(F)\right)=\left(g^{\circ} f\right)^{-1}(F)$ id $g^{*} s$-closed in $\mathrm{X}$. Hence $\mathrm{g}^{\circ} \mathrm{f}$ is contra- $\mathrm{g}^{*} \mathrm{~s}$-continuous function.

\section{Conclusion}

In this paper, we have introduced $\mathrm{g}$ *s-Homeomorphism, contra-g*s-continuous functions in topological spaces and studied some properties and this can be extended to other topological spaces like fuzzy and Bi-topological spaces. And these notions can be applied for investigating many other properties.

\section{REFERENCES}

1. S.P.Arya and T.Nour, Characterizations of s-normal spacaes, Indian J. Pure Appl.Math., 21 (1990) 717-719. 
N.Gomathi

2. K.Balachandran, P.Sundaram and H.Maki, Generalized continuous maps in topological spaces, Mem. Fac. Sci. Kochi. Univ. Ser. A. Math., 15 (1987) 51-63.

3. P.Bhattacharya and B.K.Lahiri, Semi generalized closed sets in topology, Indian J Math., 29(3) (1987) 375-382.

4. J.Dontchev, Contra continuous functions and strongly S-closed spaces, Inter. J. Math. Sci., 19(2) (1996) 303-310.

5. Govindappa Navalgi, Properties of Gs closed and sg closed sets in topology, Int. Jour of Communication in Topology, 1 (2013) 31-40.

6. S.Jafari and T.Noiri, On contra-pre continuous function, Bull. Malays. Math. Sci. Soc., (2) 25(2) (2002) 115-128.

7. N.Levine, Generalized closed sets in topology, Rend. Circ. Mat. Palerno, 19(2) (1970) 89-96.

8. S.R.Malghan, Genralized closed maps, J. Karnatak. Univ. Sci., 27 (1982) 82-88.

9. A.Pushpalatha ,K.Anitha, g*s closed sets in topological spaces, Int. J. Contem Math. Sciences, 62011(19) (2010) 917-929.

10. R.Parimelazhagan, Strongly $\mathrm{g}^{*}$ closed sets in topological spaces, Int. Jou. Math. Analysis, 6(30) (2012) 1481-1489. 